\title{
Sexual and reproductive health and HIV/AIDS risk perception in the Malawi tourism industry
}

\section{Thomas Bisika}

1. School of Health Systems and Public Health, University of Pretoria

2. Centre for Social Research, University of Malawi

Correspondence: University of Pretoria, School of Health Systems and Public Health, PO Box 667, Pretoria 0001, RSA Email: thomas.bisika@ up.ac.za

\section{Abstract}

Malawi has for a long time relied on agriculture for the generation of foreign exchange. Due to varied reasons like climate change, the Malawi government has, therefore, identified tourism as one way of boosting foreign exchange earnings and is already in the process of developing the sector especially in the area of ecotourism. However, tourism is associated with increasing prostitution, drug abuse and a whole range of other sexual and reproductive health (SRH) problems such as teenage pregnancies, HIV/AIDS and sexually transmitted infections (STIs). This paper examines the knowledge, attitudes, practices and behaviour as well as risk perceptions associated with HIV/AIDS, sexually transmitted infections and unwanted pregnancies among staff in the tourism industry and communities around tourist facilities in Malawi. The study was descriptive in nature and used both qualitative and quantitative research methods. The qualitative methods involved in-depth interviews and focus group discussions. The quantitative technique employed a survey of 205 purposively selected subjects from the tourism sector. The study concludes that people in the tourism sector are at high risk of HIV/AIDS, sexually transmitted infections and unwanted pregnancies and should be considered as a vulnerable group. The study further observes that this group of people has not adopted behaviours that can protect them from HIV/AIDS, sexually transmitted infections and unwanted pregnancies although there is high demand for voluntary counselling and testing (VCT) which offers a very good entry point for HIV prevention and treatment in the tourism sector. The study recommends that a comprehensive tourism policy covering tourists, employees and communities around tourist facilities is required. Such a policy should address the rights of HIV infected employees and the provision of prevention and treatment services for HIV/AIDS and STIs as well as a broad range of SRH and family planning services especially the condom which offers dual protection for pregnancy and STIs including HIV.

\section{Introduction}

\section{The extent of the HIV/AIDS problem}

More than 40 million people are living with HIV worldwide, including 5 million new cases in 2005 alone. Africa contributes about 25 million of this global figure. Malawi is one of the countries worst hit by the HIV/AIDS epidemic with an infection rate among the childbearing age group of $16.4 \%$. Youth aged $15-24$ claim $46 \%$ of new HIV infections of which $60 \%$ occur among girls. HIV in Malawi is mainly spread through heterosexual sex hence it is a sexual and reproductive health $(\mathrm{SRH})$ issue. Furthermore, HIV/ AIDS control efforts in Malawi are hampered by low HIV/ AIDS voluntary counseling and testing (VCT) uptake. This indicates that high HIV / AIDS knowledge is not translating to a significant behaviour change. The social and demographic impact of the epidemic is evident in the growing number of orphans and declining life expectancy at birth. Already both infant and under five mortality rates have increased and opportunistic infections like tuberculosis and meningitis are also on the increase as a direct consequence of HIV/AIDS.

\section{Tourism and Sexual and Reproductive Health}

Malawi has for a long time relied on agriculture for the generation of foreign exchange. The agriculture sector is now threatened by climate change and it has become imperative that other ways of generating the much-needed foreign exchange be explored. This is even more critical at this time when the anti-smoking lobby seems poised to jeopardize the country's major cash crop, tobacco. Against this background the Malawi government plans to develop its tourism sector in general and ecotourism in particular . Already the tourism industry is booming as demonstrated by 10 million international visitors recorded in 1997 alone, which was more than the population size of Malawi in that year. These tourist brought US $\$ 4$ million into the economy. This indicates that Malawi has a great potential for tourism development

It must, however, be acknowledged that tourism has already been associated with the spread of HIV. One explanation is that tourist facilities like hotels which often have bars, disco and other entertainment facilities are generally regarded as a business rendezvous for commercial sex workers. In such facilities people tend to engage in alcohol consumption and abuse of other mind-altering substances which can affect the maintenance of positive behaviour. Behaviours associated with drug abuse are among the main factors in the spread of HIV infection as drugs (including alcohol) can change the way the brain works by disrupting the parts of the brain that people use to weigh risks and benefits when making decisions . One of the main tourism destinations in Malawi has already recorded an HIV prevalence rate that is much higher than the national figure $(17.5 \%, \mathrm{p}<0.01)$. This should be cause for concern for the tourism industry.

Commercial sex workers usually consider tourists as affluent people and may thus deliberately target them. Similarly communities around tourist facilities may also target tourists for economic reasons. Already studies have shown that tourism increases prostitution which may result in heightened incidence of HIV if there are no safe guards in place before the tourism peaks. Other studies have also identified tourism as one of the risk factors that have facilitated the spread of HIV/AIDS along side early initiation of sexual activity, multiple sex partners, unprotected sexual intercourse, teenage pregnancy, drug abuse, presence of other sexually transmitted infections (STIs), poverty, and malnutrition . For example, in western Jamaica the spread of HIV has been attributed to increased sexual activity associated with tourism . In South Africa, where tourism is of major importance to the economy, HIV/AIDS prevalence is estimated at $25 \%$ and it is the country with the largest number of HIV infected people. Other studies have also concluded that the increase in the number of tourists attracts more people of various age groups into commercial sex work or "sex tourism" while tourism, as an industry, has been identified as facilitating the 
spread of HIV in the Caribbean .

Research has also shown that while most tourists probably do not engage in high risk activities, there were some male and female tourists who do engage in sexual encounters with multiple commercial sex workers (CSWs) and hotel employees. These encounters represent a risk to the health and economic development of those whose livelihood is dependent on the tourism industry .

In Malawi poverty is rampant and illiteracy remains wide spread especially in communities around tourist destinations. Under these conditions tourism may facilitate the transmission of HIV and sexually transmitted infections. This is because poverty and illiteracy increase people's vulnerability to HIV/ AIDS by limiting their options for a meaningful livelihood and reducing their access to information, services and commodities for HIV prevention, treatment, care and support. In order to finance their basic needs, poor people may engage in specific high-risk behaviours such as having unprotected sex with individuals like tourists whose serostatus is unknown.

The need to mainstream sexual and reproductive health including HIV/AIDS in the tourism sectors is already being addressed in some neighbouring countries to Malawi. Recently Zambia with financial support from United States signed a statement of collaboration with eight tourism companies to increase efforts to fight HIV/AIDS . By taking this step, Zambia is sending a loud and clear message to its neighbours on the need to address sexual and reproductive health issues in the tourism sector.

By its very nature, tourism tends to be a cross border phenomenon. In southern Africa many countries have no effective health systems to deliver HIV/AIDS services and many people are now trekking to countries like South Africa, mainly by road, for effective and anonymous HIV/AIDS care. Some people also travel long distances for fear that they may be stigmatized in their own communities. These itinerant health care seekers or medical tourists may require sexual and reproductive health services. Contrary to the commonly held view that it is only rich people who seek health care abroad recent studies have demonstrated that medical tourism is not limited to the affluent. A study conducted in Thailand, for example, documented low-income medical tourists. Low income medical tourists tend to travel by road and end up spreading HIV en-route to their final destinations.

The Malawi experience shows that despite the importance of the tourism sector in the socio-economic development of the country, the sexual and reproductive health concerns of the people working in the tourism industry as well as the tourists themselves have not been addressed in a comprehensive manner. The nature of work in the tourism sector, which includes night shifts and isolation in most cases, is a risk factor for the staff. The communities around tourist facilities and national parks are also a vulnerable group due to rising poverty and interaction with tourists and staff working in the tourism sectors who usually have money to pay for sex although their sero-status may be unknown.

The Ministry of Tourism, Parks and Wildlife in Malawi has embarked on a process to implement a Sexual and Reproductive Health Program for the Tourism and Travel Industry, Parks and Wildlife. The program aims at improving the quality of life for employees, mostly young men and women in tourism and travel industry and communities around national parks and resorts areas through behaviour change in the areas of sexual and reproductive health and HIV/AIDS, alcohol and drug abuse and gender equality issues.

This paper, therefore, examines the knowledge, attitudes, practices and behaviour (KAPB) as well as risk perceptions associated with HIV/AIDS, sexually transmitted infections and unwanted pregnancies among Ministry of Tourism staff and communities around tourist facilities in Malawi. This study was commissioned by the Malawi government through the Ministry of Tourism to collect baseline data for a tourism sector sexual and reproductive health workplace programme.

\section{Methodology}

The study was descriptive in nature and used both qualitative and quantitative research methodologies. This approach was appropriate to ensure that methods were triangulated. The qualitative methodology was included in order to uncover the unforeseen concerns of the target population. The data were collected by staff from the Ministry of Tourism who were planning to launch a sexual and reproductive health workplace programme for the tourism sector. Some independent interviewers were introduced in the team to collect data at Ministry of Tourism headquarters to avoid bias. A total of 8 research assistants and two supervisors were used. The research assistants were trained in research methodology and general sexual and reproductive health issues including family planning. The training took 4 days and was facilitated by a senior social scientist conversant with SRH issues from the University of Malawi. Study instruments were pre-tested as part of the training.

The qualitative methods involved in-depth interviews (IDIs) with employers and focus group discussions (FGDs) with officials from Ministry of Tourism, staff of national parks, hotels, travel agents and airlines as well as students of Malawi Institute of Tourism (MIT). Groups that entertain guests in tourist destinations and communities around national parks also participated in FGDs. The IDIs were conducted by a consultant and the supervisors. Adequate rough notes were taken in the field and available documents were also collected. A clean expanded copy of the rough notes was produced the same day to avoid recall bias.

The research assistants facilitated the FGDs, with one acting as a moderator and the other as an observer (note taker). Male and female participants were not mixed and the facilitators were of the same sex as the participants to ensure that there was free participation and maximum interaction among participants. As a rule 6-10 people participated in each FGD to allow for maximum participation and interaction. A discussion guide was prepared for this purpose and had standard questions which were meant to generate discussion. FGDs were recorded for quality control purposes and lasted between forty-five minutes and one hour. A total of 12 IDIs and 20 FGDs were conducted.

The quantitative technique employed a survey of 205 subjects from Ministry of Tourism, hotels, rest houses, national parks and motels. The sample size was determined assuming that the prevalence rate for HIV was $15 \%$, while allowing for a margin of error of $10 \%$ and a confidence interval of $95 \%$. 
The required sample was thus computed as follows:

$\mathrm{N}=\frac{\mathrm{p}(100-\mathrm{p})}{(\sigma \mathrm{x}) 2}=\frac{15(100-15)}{(\sigma \mathrm{x}) 2}=\frac{1275}{(25)}=51$

Where $\sigma \mathrm{x}$ is standard deviation

The study was conducted in 4 districts which have important tourism activities. These districts were Blantyre, Mangochi, Lilongwe and Nkhata-bay. A total of 51 subjects were selected from each of these districts to capture within district variations although an extra subject was interviewed Mangochi. In each district one hotel, one motel or rest house were sampled. In one district a national park and game reserve were included. In Blantyre a tourism education institution and a travel agent were also included. The sample for the survey was dominated by men $(45.2 \%)$ followed by women $(25.3 \%)$ and Boys (19.1\%). The representation of girls was limited $(10.4 \%)$ which is a major limitation of this study as this is the group most in need of sexual and reproductive health services. The overall gender differential in the participation rates was mainly due to the fact that there are fewer women than men in the tourism sector. Boys and girls were defined as males and females aged 10-24 respectively in order to harmonized with the national definition of youth. The instrument had mostly standard items with a few that were programme specific. A total of 32 items were on the questionnaire and 10 of these were contingency questions. The questions were mostly closed-ended with a few openended ones.

The units visited during field work were purposively selected and the actual subjects were picked depending on sex, availability and department to increase variability based on a quota that was predetermined in consultation with the Ministry of Tourism. This was designed in such a way that headquarter staff did not dominate the sample. The data collection was done in 2004 and was completed in 21 days. The qualitative data collection preceded quantitative data collection so that results from the former could inform the latter.

Content analysis for the qualitative information was done manually using the search and code method (Hardon et al, 1995: 281-282). This was implemented by devising codes based on the study objectives followed by ordering of the information as some of the information was fragmented. All the data relating to a particular code were marked with that code. After coding all the information that was given the same code was then listed in a specially designed matrix. Quantitative data analysis was done using Statistical Analysis Systems (SAS) and Statistical Package for Social Scientists (SPSS). Since the study was descriptive in nature, only percentages were generated and statistical control was exercised using cross tabulations.

\section{Ethical Considerations}

The research team obtained a verbal informed consent from all the subjects after explaining the purpose of the study. The information that was collected from the subjects was not revealed to anyone and the subjects were interviewed in places where they were neither seen nor heard by other people to guarantee privacy. No promises were made on benefits of the study to avoid coercion. The subjects were told that they were free to withdraw at any stage if they felt that they were no longer interested in the study.

\section{Results}

\section{HIV/AIDS and STI Knowledge, Behaviour and Risk Perception}

The workers in national parks reported that they work in isolated camps where they may spend many days away from home a thing they thought could increase their vulnerability to HIV and other SRH problems. One participant actually observed that "even our spouses may be tempted to engage in other activities because they know we are not there." Those in the accommodation establishments reported that they consider themselves at risk because they work in night shifts at times and interact with guests. They were, however, quick to acknowledge that existing regulations do not allow them to associate with guests.

Subjects who took part in the survey identified some groups which they thought were at risk of HIV/AIDS. These included people with multiple partners and those who can't control themselves. All the officials at the Ministry of Tourism were of the view that anybody can get HIV. This proportion was much lower in the hotels and wild life establishments (Table 1).

Although people working in the tourism sector were not specifically mentioned as a high risk group, when asked directly $41.5 \%$ of the subjects mentioned that the fact that they are working in the tourism and travel industry, Parks

Table 1: Survey results on risk perception of HIV/AIDS by nature of tourism establishment (n=205) (\%)

\begin{tabular}{|c|c|c|c|c|c|}
\hline Category Risk Group & $\begin{array}{l}\text { Ministry of } \\
\text { Tourism }\end{array}$ & Hotel/Resthouse & Parks and Wildlife establishments & Other Companies & Overall \\
\hline Bar girl & 8.3 & 5.2 & 8.3 & 14.8 & 6.9 \\
\hline Truck driver & .0 & 2.6 & 8.3 & 3.7 & 2.9 \\
\hline $\begin{array}{l}\text { Those multiple } \\
\text { partners }\end{array}$ & 8.3 & 16.3 & 8.3 & 7.4 & 14.2 \\
\hline Children/babies & .0 & 2.0 & .0 & .0 & 1.5 \\
\hline Students & .0 & .7 & 8.3 & .0 & 1.0 \\
\hline Anybody & 100.0 & 64.7 & 50.0 & 74.1 & 67.2 \\
\hline Soldiers & .0 & 2.0 & 16.7 & .0 & 2.5 \\
\hline Youth & .0 & 6.5 & 33.3 & 3.7 & 7.4 \\
\hline $\begin{array}{l}\text { People who can not } \\
\text { control themselves }\end{array}$ & .0 & 13.7 & 33.3 & 7.4 & 13.2 \\
\hline Other & 8.3 & 7.2 & .0 & .0 & 5.9 \\
\hline
\end{tabular}


and Wildlife puts them at an excess risk for HIV/AIDS, pregnancy and STIs. Furthermore, during the FGDs staff of the tourism establishments acknowledged that they have not been reached by awareness campaigns that characterized the last decade. Despite this lack of information and services, HIV/AIDS awareness in the tourism sector is almost universal. More than a quarter of the people $(25.7 \%)$ in the industry learnt about HIV/AIDS from health workers but the majority learnt this from the radio $(61.2 \%)$.

Overall $83.9 \%$ of the subjects reported changing behaviour after hearing about AIDS with a large proportion of people in parks and wildlife reporting such a change. About one quarter of the subjects had sex with a person who was not their regular partner. Of these people $40 \%$ had sex with more than two partners and $73.8 \%$ reported using condoms all the time in such encounters.

With respect to alcohol and drug abuse, the survey found that $38.3 \%$ of those in the tourism industry take alcohol of whom $9.1 \%$ drink on a daily basis and $48.1 \%$ on a weekly basis. Smoking was not as common (only 12.8\%). In this study besides narcotic drugs, tobacco and alcohol were also included as drugs of abuse and drug abuse was defined as the use of any drug of abuse on a regular basis .

Some of the subjects have had an STI before (17.6\%) despite the fact that $98 \%$ of them reported that STIs can be avoided. The subjects contended that STIs should be treated as they can cause infertility (41.3\%), facilitates HIV transmission $(19.0 \%)$ and they are very painful $(17.9 \%)$. In this respect the subjects were asked about the sources of STI treatment that they knew of. The public health centre was the most popular source after being mentioned by $92.1 \%$ of the subjects followed by private clinics $(33.0 \%)$. Almost all participants would tell their partner if they had an STI and would bring their partner for treatment. This was more pronounced in national parks and wild life where virtually every body would bring their partner for treatment.

People who participated in the FGDs knew a number of ways to avoid STIs and HIV/AIDS which included using condoms, abstinence and faithfulness. Those who participated in the survey also identified abstinence, avoiding sex with multiple partners and using condoms as ways of avoiding HIV/AIDS. The most popular method for avoiding HIV/ AIDS was not having sex, followed by not having sex with multiple partners and using condoms (Table 2).
Voluntary Counseling and Testing (VCT)

Voluntary counseling and testing (VCT) is an important entry point for HIV prevention and treatment and is also an important indicator of behaviour change. Almost all the people who work in the tourism sector knew where one can go for voluntary counseling and testing (VCT) and $85.2 \%$ of the subjects were willing to be tested. Those belonging to accommodation units like hotels and lodges were more likely to express their willingness to go for VCT than their colleagues in other categories. In this study, it was observed that $89.7 \%$ of the subjects wanted to know the HIV test results but those in the accommodation units were less willing to want to know the results.

With respect to disclosure of results, overall $93.6 \%$ of the subjects would tell their partner if they were positive and more than two thirds $(67.3 \%)$ would tell their boss. The people in Parks and Wildlife were more likely to mention that they would tell their boss than those in the accommodation units.

\section{Family Planning}

Most of the subjects who were surveyed knew more than one family planning method. The most popular method was injection $(64.5 \%)$ followed by pill $(61.6 \%)$ and condom $(58.6 \%)$. Some of the subjects reported that they had used a family planning method at some point in their lifetime. These people mostly used injection (about 30\%), condoms (almost a quarter of the subjects), and pill (more than a fifth). About a quarter $(23.2 \%)$ of the subjects did not use any method in their lifetime.

For purposes of programming it was necessary to ask the subjects about the FP methods they are presently using. It was discovered that more than a third of the subjects were not using a method. About a quarter were using injection while a fifth was using condoms. The most popular source for FP methods was cited as the public health centre.

\section{Sources of Condoms}

The condom is one of the most important ways of avoiding STIs, HIV/AIDS and unwanted pregnancies as it provides dual protection. To assess the availability and accessibility of the condom, the subjects were requested to cite some sources of condoms and these included grocery store $(80 \%)$, health centre $(61 \%)$ and Banja La Mtsogolo-a private clinic run by a non-governmental organization (21.5\%) among

Table 2: Survey results on how HIV/AIDS can be avoided (N=205) (\%)

\begin{tabular}{|l|l|l|l|l|l|}
\hline Method & Ministry of Tourism & Hotel/Resthouse & $\begin{array}{l}\text { Parks and Wildlife } \\
\text { establishments }\end{array}$ & Other companies & Overall \\
\hline Using condoms & 16.7 & 36.7 & 46.2 & 51.9 & 38.1 \\
\hline Avoiding sex with multiple partners & 16.7 & 47.3 & 30.8 & 14.8 & 40.1 \\
\hline Avoiding sharing razor & 16.7 & 23.3 & 38.5 & 29.6 & 24.8 \\
\hline Avoid sharing tooth brush & 16.7 & 10.0 & 23.1 & 14.8 & 11.9 \\
\hline Avoid kissing & .0 & .7 & 15.4 & .0 & 1.5 \\
\hline Avoid sharing beddings & .0 & .0 & 7.7 & .0 & .5 \\
\hline Blood testing before marriage & .0 & 4.0 & 15.4 & 3.7 & 4.5 \\
\hline Not having sex & 66.7 & 41.3 & 61.5 & 66.7 & 47.5 \\
\hline Sterilized needles & 8.3 & 8.7 & 15.4 & 11.1 & 9.4 \\
\hline Other & 8.3 & 8.7 & 7.7 & 18.5 & 9.9 \\
\hline
\end{tabular}




\begin{tabular}{|l|l|l|l|l|l|}
\hline Category & Ministry of Tourism & Hotel/Resthouse & Parks and Wildlife establishments & Other companies & Overall \\
\hline Grocery/shop & 81.8 & 78.1 & 92.3 & 84.0 & 80.0 \\
\hline Health centre & 54.5 & 62.3 & 76.9 & 52.0 & 61.5 \\
\hline Banja la Mtsogolo & 9.1 & 22.5 & 30.8 & 16.0 & 21.5 \\
\hline Friends & .0 & 1.3 & 7.7 & 8.0 & 2.5 \\
\hline Hotel/rest houses & .0 & 17.2 & 23.1 & 12.0 & 16.0 \\
\hline Others & 18.2 & 7.9 & .0 & 20.0 & 10.5 \\
\hline
\end{tabular}

several others (Table 3).

Although there were a number of sources of condoms, more than a third of the subjects $(36.8 \%)$ admitted that condoms were not easy to get. With respect to use, more than three quarters of the subjects $(76.2 \%)$ would accept if partner suggested condom use.

\section{Attitude towards HIV/AIDS}

Overall $93.6 \%$ of the subjects who took part in the survey reported that they would look after an AIDS patient. More than two thirds of them knew someone who had died of AIDS (68.8\%) and some of them were related to the people who died $(43.2 \%)$. A significant proportion of the people who took part in the survey $(85.1 \%)$ also think that HIV positive people should continue working. With respect to training, the subjects would like HIV infected people to be given training opportunities $(87.4 \%)$. They were also of the view that people living with HIV should be promoted $(85.4 \%)$ and should get a loan $(80.5 \%)$ just like any other employee. These issues were picked up during the discussion on policy issues which is presented below.

\section{Policy issues}

According to the study informants there was no specific policy on sexual and reproductive health and HIV/AIDS in the tourism sector that the FGD participants knew of, however, the FGDs conducted at the Ministry of Tourism observed that the Wildlife Policy provides a good starting point for a policy on HIV/AIDS as it cites provision of a "healthy living and working environment for the people of Malawi". The Tourism Policy, however, does not specifically mention health but in the Human Resources Development section the policy mentions that there is need to "provide a greater pool of skilled labour force into the industry". According to the informants this may entail the need to protect these people from HIV/AIDS. The staff acknowledged that standard procedures for communicating policy to staff exist which included memos, circulars displayed on boards and meetings. These communication methods were, however, not appropriate for those in the field as well as communities around tourist facilities and establishments.

Only staff from the Ministry of Tourism acknowledged that they have access to SRH services while those in hotels and parks lamented that they have no access to SRH information due to the fact that they work in isolated environments.

The staff at the Ministry of Tourism acknowledged that it was high time that a sexual and reproductive health workplace programme for the tourism sector was put in place. In terms of sustainability, the managers agreed that the workplace programme may not be easy to sustain financially but they suggested that the Ministry of Tourism's budget should include condoms to ensure sustainability. Some officials indicated that the behaviour change that will come from the workplace programme would remain long after the project.

\section{Discussion}

The people who are in the tourism industry consider themselves at risk for HIV, STIs and unwanted pregnancies. However, the identification of risk groups that does not include tourists may create false security among those who are working in the tourism industry. The fact that some of them are even having casual sex without using condoms puts them at a heightened risk for HIV, STIs and unwanted pregnancies. Some of them have had STIs before which suggests that they have not adopted protective behaviours. This could be as a result of a general lack of information on SRH and lack of access to HIV and SRH services such as VCT, condoms and family planning. These findings complement those found in the Caribbean countries by emphasizing that people who work in the tourism industry are just as vulnerable as the tourists themselves (Lamptey et al, 2006; Kovaleski, 1998). This is critical because studies hitherto have concentrated on tourism and prostitution (sex tourism).

The condom is not popular in the prevention of HIV/AIDS and STIs as well as avoidance of pregnancy. This explains why the subjects were ready to state sources of condoms but reported that condoms were difficult to get perhaps due to stigma as condoms are usually associated with extramarital sex. The dual protection offered by the condom was not acknowledged in family planning method selection. This seems to suggest that the dual protection that is offered by the condom is not being taken advantage of hence the elevated risk. The high percentage of subjects reporting abstinence as a way of avoiding HIV seems to suggest that the people were giving more socially desirable answers which means that they have hot yet started talking about sexual and reproductive health openly.

For both hotels and national parks, access to SRH services was still limited and the participants from these units did not report provision of such services during the focus group discussions. This suggests that HIV/AIDS education has only targeted the Ministry of Tourism staff at the expense of the staff working in hotels and wildlife establishments who might even be more vulnerable.

The main challenge in reaching people in the tourism sector with HIV/AIDS, Sexually Transmitted Infections (STIs) and Family Planning (FP) information is the fact that these people are isolated and in some cases access to hotels is subject to permission for security reasons or otherwise. This calls for a review of existing behaviour change communication programmes as well as other public health education initiatives. Such programmes and initiatives should recognize 
people working and interacting with the tourism sector as a vulnerable group.

An urgent need for a Tourism Policy is apparent. Such a policy should address the rights of HIV infected employees and include the provision of prevention and treatment services for HIV/AIDS and STIs. Family planning services should also be provided especially the condom. The policy should cover employees, tourists, communities around tourist facilities, students at the Malawi Institute of Tourism and groups that perform cultural dances as a way of entertaining tourists.

\section{Conclusion}

The people who work and interact with the tourism sector are at a greater risk of HIV, STIs and unwanted pregnancies. Although they consider themselves at risk, these people have not yet adopted behaviours that can protect them from HIV/AIDS, sexually transmitted infections and unwanted pregnancies. This calls for an urgent HIV/AIDS RHS tourism policy for the tourism sector that will help meet health needs of stake holders as revealed in the study.

\section{References}

1. UNAIDS. (2006). 2006 Report on the global AIDS epidemic

2. UNAIDS. (2004). Malawi - Epidemiological Fact Sheet on HIV/ AIDS and Sexually Transmitted Infections, 2004 Update [cited 8 Oct 2005]. Available from: http://www.unaids.org/html/pub/ publications/fact-sheets01/malawi_en_pdf.htm

3. Barden-Ofallon, J., deGraft-Johnson, J., Bisika, T., Benson, A. \& Tsui, A. (2004). Factors associated with HIV/AIDS Knowledge and Risk Perception in Rural Malawi, AIDS and Behaviour. 8(2), 131-140.

4. de Graft-Johnson, J., Paz-Soldan, V., Kasote, A. \& Tsui, A. (2005). HIV Voluntary Counseling and Testing Service Preferences in a Rural Malawi Population. AIDS and Behaviour. 9(4), 475-484.

5. Malek, A \& T.Bisika. (2001). Food Assistance to HIV/AIDS Infected and affected Individuals: A Revised Programme. WFP/UNAIDS: Lilongwe.

6. Mkoka, C. (2003). Malawi Plans to Jumpstart Economy with Ecotourism. Environmental News Service, http://www.ensnewswire.com/ens/jan2003/2003-01-09-02.asp accessed on January 18,2008

7. World Investment News. (2008).Tourism Investment for the Future: Malawi available on http://www.winne.com/malawi/cr10.html accessed on January 18, 2008

8. Prideaux, B. R. \& Agrusa, J. (2002) Tourism and the threat of HIV/ AIDs in Vietnam. Asia Pacific Journal of Tourism Research, 7 1: $1-10$

9. National Institute on Drug Abuse. (2007).Learn the link between drug abuse and the spread of HIV in the United States. Available on http://hiv.drugabuse.gov/english/learn/overview.html accessed on November 19, 2007.
10. Hoffman, I. F., Tsui, A., de Graft-Johnson, J., Bisika, T., Feluzi H. \& Kazembe, P.N. (2003). Reducing the STI burden in Rural Malawi : STD screening, Case and Contact Treatment, and Condom Promotion. University of North Carolina: Chapel Hill.

11. Bauer, T., \& McKercher, B. (2003). Sex and Tourism: Journeys of Romance, Love, and Lust. New York: Haworth Hospitality Press/ Haworth Press

12. Olukoga, I.A. (2004).Epidemiologic trends of HIV/AIDS in Jamaica. Rev Panam Salud Publica. 15(5), 358-63

13. Figueroa, J.P., Brathwaite, A., Ward, E., DuCasse, M., Tscharf, I., Nembhard. O., et al. (1995). The HIV/AIDS epidemic in Jamaica. AIDS. 9(7), 761-768

14. Herholdt-Smith, J. (2003) "A Research Study on the Impact of HIV/ AIDS in the Hospitality Industry in Africa." Available on http:// www.africacncl.org/HIV_AIDS/about_aai/sectors/hospitality.asp accessed on April 16, 2009

15. Stillwaggon, E. (2000). HIV transmission in Latin America: comparison with Africa and policy implications. S Afr J Econ. 68(5), 985-1011

16. Kovaleski, S.F. (1998). Poverty, drug abuse fuel Caribbean AIDS outbreak. AIDSlink. 49, 6-7

17. Forsythe S, Hasbun J \& M Butler de Lister M. (1998).Protecting paradise: tourism and AIDS in the Dominican Republic. Health Policy and Planning, Vol 13, 277-286

18. World Bank. (2002). Jamaica HIV/AIDS Prevention and Control Project (second phase of the multi-country HIV/AIDS prevention \& control APL for the Caribbean). Washington, D.C.: World Bank.

19. Lamptey, P.R., Johnson, J.L. \& Khan, M. (2006). The Global Challenge of HIV and AIDS. Population Bulletin, Vol. 61, No. 1.

20. Kaiser Family Foundation. (2007). HIV/AIDS | U.S., Zambia Sign Agreement To Partner With Tourism Companies To Fight HIV/AIDS. November 13, 2007 in Xinhua News Agency reports. http://www.globalhealthreporting.org/article.asp?DR_ID=48844 accessed on January 21, 2008.

21. Rosen S, Hamazakaza P, \& Long L. (2006). "The impact of HIV/AIDS on the tourism sector in Zambia." Centre for International Health and Development Boston University and Farming Systems Association of Zambia. Available on http://sph.bu.edu/images/stories/scfiles/ cih/ZambiaimpactofAIDSontourismfinalreport24Feb2006.pdf accessed on April 16, 2009.

22. Lazarus, M.G. (2004). Medical Tourism for HIV/AIDS Care in Northern Thai Communities. Int Conf AIDS

23. Ministry of Tourism. (2002). Wildlife Policy. Lilongwe

24. Hudelson, P. (1995). "Guidelines for Conducting a Rapid Ethnographic Study of Malaria Case Management." Second Fieldtest Version. Geneva: Programme for Research and Training in Tropical Diseases

25. Hardon A., Boonmongkon P., Steefland P., Tan M.L., Hongvivatana T., Geest T van der, Staa, A., \& Varkevisser C. (1995). Applied Health Research Manual: Anthropology of Health and Health Care. Netherlands: University of Amsterdam.

26. Bisika, T. Konyani, S. \& Chamangwana, I. (2004). Drug Abuse and HIV/AIDS Rapid Assessment Study. Zomba: Centre for Social Research

27. Bisika, T. (2008).Cultural Factors that Affect Sexual and Reproductive Health in Malawi. Journal of Family Planning and Reproductive Health Care. 34(2): 79-80 